\title{
Thermal plumes above hot sources: characterization and capture efficiency
}

\author{
René Devienne ${ }^{1, a}$ and Jean-Raymond Fontaine ${ }^{2}$ \\ 1 LEMTA, CNRS UMR 7563, 2 avenue de la Forêt de Haye, BP 160, 54504 Vandoeuvre-lès-Nancy Cedex, France \\ 2 Institut National de la Recherche et de la Sécurité, Département Ingénierie des Procédés, Rue du Morvan, CS 60027, \\ 54519 Vandœuvre Cedex, France
}

Received 30 March 2015, Accepted 28 January 2016

\begin{abstract}
Many industrial processes use or generate thermal sources. The release of heat is generally accompanied by the dispersion of pollutants in the working area, which can lead to occupational diseases in the long-term. The characterisation of plumes stemming from thermal sources by natural convection is required to define the adequate dimensions for ventilation systems (fume collecting hoods and general displacement ventilation systems), used to clean air at work stations. The aim of this paper is to present the methods and techniques that can be used in ventilation engineering to analyse and manage industrial applications. The results presented concern the thermal and dynamic characterisation of plumes generated by different types of sources (horizontal disks, vertical cylinders, horizontal rectangular surfaces). New results concerning the efficiency of a fume extraction hood placed above a flat, rectangular thermal source was analysed as a function of the height and position of the hood in relation to the source and the extraction fan flow rate. These results are of practical interest. A numerical approach of temperatures in the proximal zone is also proposed.
\end{abstract}

Key words: Hot sources / plumes / temperature / velocity / concentration fields / capture efficiency

\section{Introduction}

A number of industrial installations implement devices that can be considered as heat sources, including machine tools, molten metal crucibles, and so on. Since air density varies with temperature, these sources inevitably generate thermal plumes which develop above them. These air flows must be processed to regulate the ambient working temperature and also because the flows may be the vector of different pollutants emitted in the immediate proximity of the heat source. Generally, processing is carried out using direct capture methods and possibly filtration and discharge into the external environment. Recovery of the energy extracted may also be an interesting option to be considered. The position of the suction inlet of the extraction hood needs to be accurately defined for an efficient installation of a smoke capture system. The flow rate and the spread of the plume at the correct given height above the source must be estimated to enable the correct choice of dimensions and exhaust flow for the hood. Capture efficiency of the magnitude defined below strongly depends on the air flow rate

\footnotetext{
${ }^{a}$ Corresponding author:

Rene.Devienne@ensem.inpl-nancy.fr
}

of the extraction system, the dimensions of the extraction inlet and the possible shift of the system in relation to the vertical axis of the plume.

The aim of this article is to present the methods (calculation of flows, modelling of fields, and so on) and resources (ventilation unit, sources, materials, and so on) that can be proposed to ventilation engineers to analyse and characterise thermal plumes. The installation of these resources will be illustrated by examples considered to be particularly interesting in this context. A short list of references will also be presented to review the different possible theoretical approaches and the limits thereof and to present characteristic results particularly regarding capture efficiency.

\section{Literature review}

Many authors with different academic and practical objectives have focused on the issue of plume development. The works of Schmidt [1], showing the conical shape of the plume, were followed by those of Morton et al. [2] who initially proposed 'top-hat' shaped profiles and then 


\section{Nomenclature}

\begin{tabular}{|c|c|}
\hline$A, B$ & Half-axes for ellipses in the model (m) \\
\hline$b_{D}, b_{T}, b_{m}$ & Dynamic, thermal and mass radii (for velocity, temperature and concentration) $(\mathrm{m})$ \\
\hline$\Delta C_{c}$ & Maximal difference of concentration (ppm) \\
\hline$C_{1}, C_{1}^{\prime}, C_{2}, C_{3}$ & Concentrations in the efficiency formula (ppm) \\
\hline$C_{p}$ & Specific heat capacity of air $\left(\mathrm{J} \mathrm{kg}^{-1} \cdot \mathrm{K}^{-1}\right)$ \\
\hline$g$ & Acceleration due to gravity $\left(\mathrm{m} . \mathrm{s}^{-2}\right)$ \\
\hline$\dot{m}_{e}, \dot{m}_{c}$ & Mass rates at the source and captured $\left(\mathrm{kg} \cdot \mathrm{s}^{-1}\right)$ \\
\hline$l$ & Width of an element for the rectangular sources $(\mathrm{m})$ \\
\hline$L$ & Length of an element for the rectangular sources $(\mathrm{m})$ \\
\hline$P_{c}$ & Convected power from the thermal source (W) \\
\hline$p_{c}$ & Convected power by length unit $\left(\mathrm{W} \cdot \mathrm{m}^{-1}\right)$ \\
\hline$Q_{a}$ & Extracted flow rate $\left(\mathrm{m}^{3} \cdot \mathrm{s}^{-1}\right)$ \\
\hline$Q_{v}$ & Flow rate convected by the plume $\left(\mathrm{m}^{3} \cdot \mathrm{s}^{-1}\right)$ \\
\hline$r_{D}$ & Ratio of flow rates \\
\hline$\Delta T$ & Temperature difference between plume and ambient air at height $z(\mathrm{~K})$ \\
\hline$\Delta T_{c}$ & Temperature difference between plume centre and ambient air at same height $(\mathrm{K})$ \\
\hline$T_{a}$ & Injection air temperature $(\mathrm{K})$ \\
\hline$T_{s}, T_{s 1}, T_{s 2}$ & Surface temperatures of heat source $(\mathrm{K})$ \\
\hline$u$ & Radial velocity $\left(\mathrm{m} . \mathrm{s}^{-1}\right)$ \\
\hline$w_{c}$ & Velocity at plume centre $\left(\mathrm{m} . \mathrm{s}^{-1}\right)$ \\
\hline$w$ & Vertical component of plume velocity $\left(\mathrm{m} . \mathrm{s}^{-1}\right)$ \\
\hline$(x, y, z)$ & Cartesian coordinates $(\mathrm{m})$ \\
\hline$\left(x_{c}, y_{c}\right)$ & Coordinates of plume centre at a given height $z(\mathrm{~m})$ \\
\hline$z_{v}$ & Virtual origin coordinate $(\mathrm{m})$ \\
\hline \multicolumn{2}{|r|}{ Greek characters } \\
\hline$\alpha$ & Entrainment coefficient for a plume \\
\hline$\beta$ & Volume coefficient of thermal expansion $\left(\mathrm{K}^{-1}\right)$ \\
\hline$\lambda=b_{T} / b$ & Ratio of thermal radius $b_{T}$ to dynamic radius $b$ \\
\hline$\eta$ & Efficiency \\
\hline$\rho$ & Air density $\left(\mathrm{kg} \cdot \mathrm{m}^{-3}\right)$ \\
\hline$\rho_{a}$ & Density of ambient air $\left(\mathrm{kg} \cdot \mathrm{m}^{-3}\right)$ \\
\hline
\end{tabular}

self-similar Gaussian solutions which are valid for an established flow.

McKernan et al. [3] provided a velocity evolution law which they then compared to their experimental data and to the recommendations of the American Conference of Governmental Industrial Hygienists and those of Hemeon [4].

In industrial practice, the variation between the temperature at the centre of the plume and the ambient temperature can be quite large especially in the immediate proximity of heat sources. In this situation, the variations of the specific density of the air are no longer conform to Boussinesq's approximation, as indicated by Rooney and Linden [5].

The work of Morton et al. [2] paved the way for two theoretical models which can be used to obtain a complete dynamic and thermal description of plumes due to natural convection. They use the cases of a point source and a uniformly heated infinite linear source. The point source case corresponds to an idealized situation of heat production in a zone the dimension of which is infinitesimal small, for the linear source, heat production concerns a line with a constant power per length unit. A current formulation of the results obtained is proposed by [6].

Briefly, the solutions put forward for the dynamic and thermal fields are self-similar functions

$$
\begin{aligned}
\Delta T(x, y, z) & =\Delta T_{c}(z) \exp \left(-(r /(\lambda b))^{2}\right) \\
w(x, y, z) & =w_{c}(z) \exp \left(-(r / b)^{2}\right)
\end{aligned}
$$

These two expressions define the dynamic radius $b$ and $b_{\mathrm{T}}=\lambda b$, the thermal radius, two functions of $z, \lambda$ being considered as a constant.

In Appendix 1, are listed all the characteristics of plumes, according to the works of Schmidt [1] and Morton et al. [2]. However, it is useful at this point to recall the hypothesis which led to the results given. These were:

- axisymmetry (for the case of a point source) or independence relatively to y coordinate (case of the infinite linear source);

- the preponderance of turbulent stresses in relation to purely viscous stresses;

- the existence of a constant entrainment coefficient $\alpha$; 
- constant heat capacity and air conductivity, variation of the specific density of the air obeying Boussinesq's approximation.

In industry, real sources can be very different from the academic models presented. In addition, it may not be possible to ensure conformity with certain of the above conditions. However, the solutions presented can be used efficiently provided that different corrections are employed and that the domain used is specified. The most important correction is related to the notion of virtual origin. This correction relies on the fact that in the vicinity of real sources-with finite dimensions-the structure and other characteristics of the plume are still dependent on the geometry of the source. At a sufficient distance from the source, experimental results show that the velocity and temperature fields exhibit a comportment which is that of the formulae given in Appendix 1, but modified by substitution of $z$ by $z-z_{v}$, with $z_{v}<0, z_{v}$ being a function of the source geometry.

As for practical applications, an indication of the expression of virtual origin is given in the Industrial Ventilation Manual issued by the American Conference of Governmental Industrial Hygienists ACGIH [7], that is to say $z_{v}=-(2 D)^{1.138}$. In the Industrial Ventilation Design Guidebook [8], one can find $1.7<-z_{v} / D<2.1$, $D$ being a characteristic length of the source, usually a diameter.

It is also worth noting that, while other non-linear solutions have been proposed, the model formulated does not provide a full description of phenomena, as detailed by Faneloop [9].

\section{Industrial process}

Here, we give a brief presentation of a real situation in an industrial context. This example concerns a foundry company whose main activity is aluminium and zamac die casting, using a gas-operated melting furnace with a capacity of $250 \mathrm{~kg}$. Zamac is used to designate an alloy of zinc, aluminium $(3.7 \%<$ mass concentration $<4.3 \%)$ and magnesium $(0.025 \%<$ mass concentration $<0.06 \%)$. Die casting is a metal casting process that is characterized by forcing molten metal under high pressure into a mold cavity. The furnace external diameter is about 60 $\mathrm{cm}$ (see Fig. 1). The figure shows the free surface of the molten metal and also the linear system supporting the temperature measurement probes.

From a practical standpoint, the designer is generally only able to determine the temperature field above the furnace, since thermal probes are commonly used. The velocity values within the plume are rarely measured since they need the use of specialized apparatus not available in an industrial context (see Fig. 2).

The temperature profiles can be represented by an expression of the shape:

$$
T=T_{a}+\Delta T_{c} \exp \left(-\left(\frac{x-x_{0}}{b_{T}}\right)^{2}\right)
$$

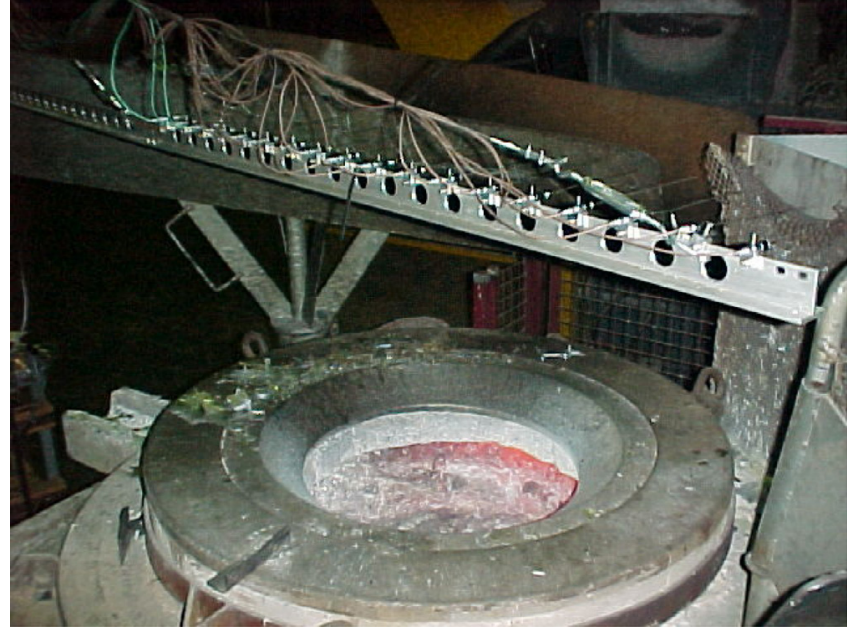

Fig. 1. Temperature measurement probes above an aluminium melting furnace.

where $T_{a}$ is the ambient or external temperature, $T_{c}$ the maximum temperature observed in the plume at a given height above the source which defines the difference $\Delta T_{c}=T_{c}-T_{a}$. The parameter $\mathrm{b}_{T}$ stands for a length characterizing the plume expansion, for a given horizontal plane. As shown in Figure 1, the temperature probes are fixed on a ruler parallel to a diameter of the free metal surface. Figure 2 gives temperature curves with an arbitrary origin for the $x$ coordinate, $x_{0}$ corresponds to the maximum temperature.

The values of the parameters shown (see Fig. 3) are obtained using a least squares minimization, a method which provides the maximum variation of temperature $\Delta T_{c}=T_{c}-T_{a}$, the position of the central point $x_{0}$ and, secondarily, the thermal radius $b_{T}$.

To determine the value of the flow rate at a given height, which is the major parameter for pollutant capture, the designer needs to know the power convected by the furnace. The dimensions involved and the temperature of the molten metal can be used to estimate this parameter by using classical thermal correlations. At this stage, the flow rate rising to a given height can be determined using practical formulae:

$$
\begin{aligned}
& Q_{v}(z)=2 P_{c} /\left(\rho C_{p} \Delta T_{C}\right) \\
& Q_{v}(z)=5 \times 10^{-3} P_{c}^{1 / 3}\left(z-z_{v}\right)^{5 / 3}
\end{aligned}
$$

where $\rho, C_{p}$ are respectively density and heat capacity of the air in the external conditions.

Here, $P_{c}$ stands for the total power produced by the source. These formulae can be obtained from the expressions given in Appendix 1. It must be noticed for Equation (4) that the height does not appear explicitly. In Table 1 , the second column shows the corresponding flow rates $\mathrm{Q}_{v 1}$. Nonetheless, we need to bear in mind that Equation (5) requires an additional hypothesis to assign a value to $z_{v}$. The fourth column in Table 1 gives the corresponding flow rates $Q_{v 2}$. It is then possible to estimate the maximum velocity $w_{c}$ of the air at the centre of the 
R. Devienne and J.-R. Fontaine: Mechanics \& Industry 17, 609 (2016)

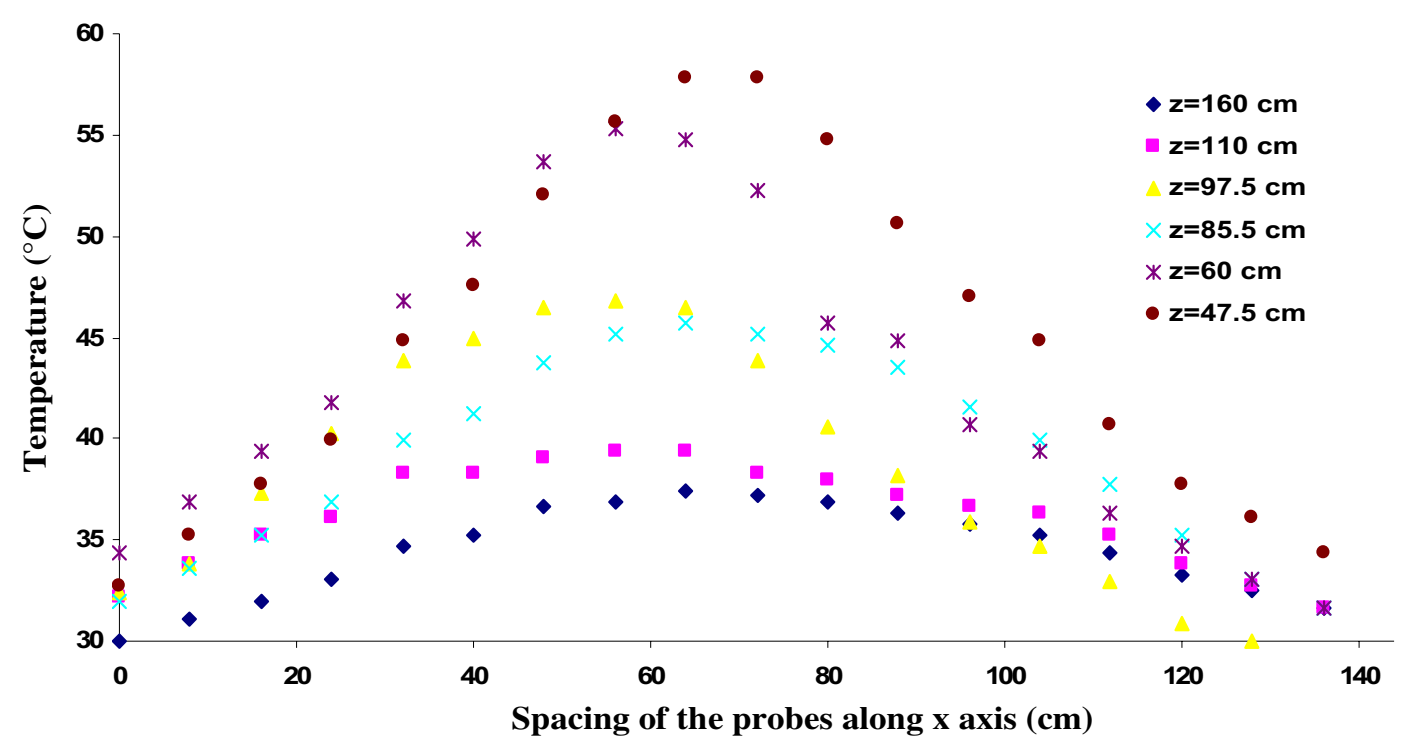

Fig. 2. Distribution of temperatures above the furnace, $z$ being the height above the liquid aluminium surface.

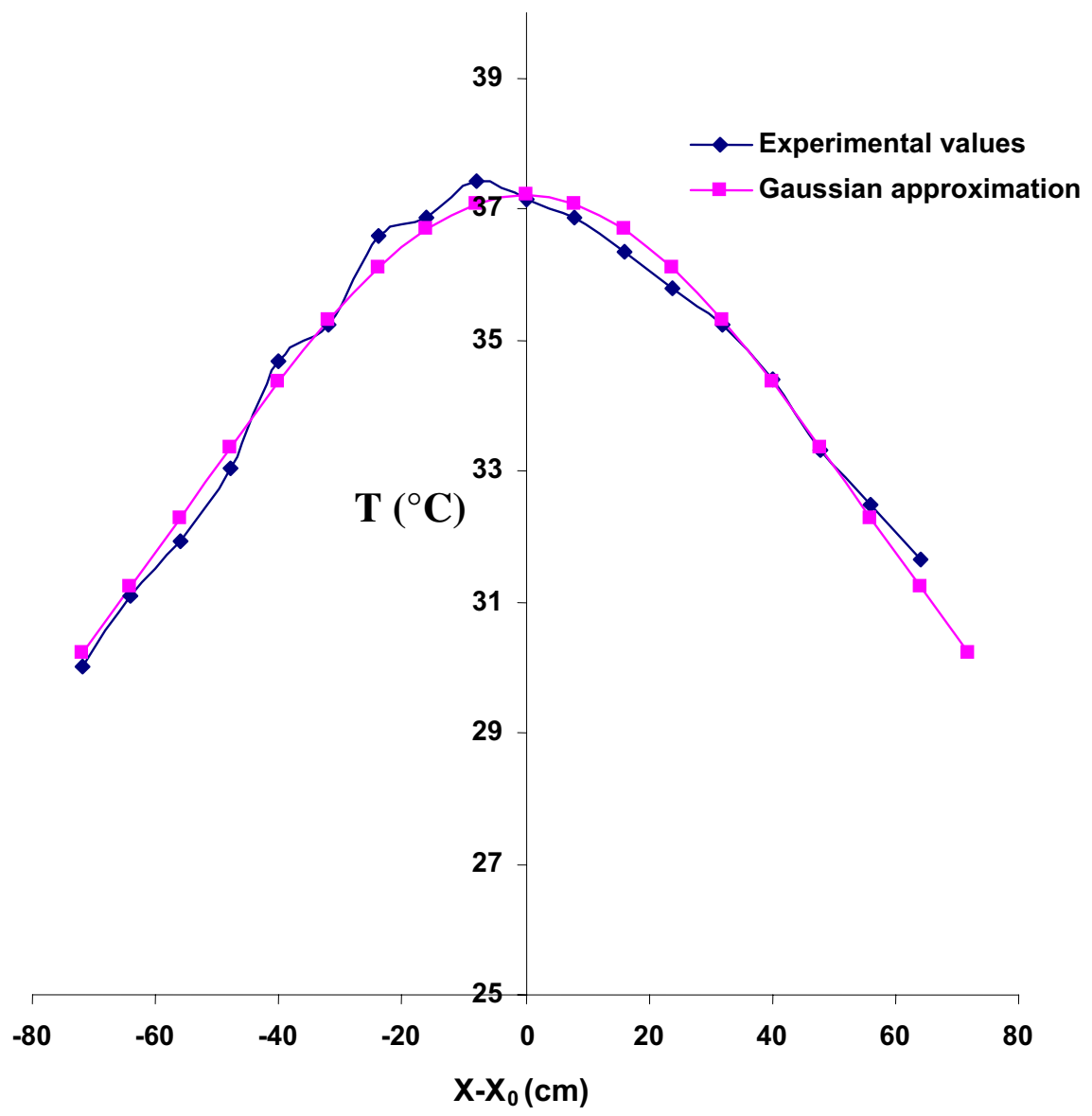

Fig. 3. Measured and estimated temperature $T$ at $z=0.475 \mathrm{~m}$ above the source versus a centred abscissa $x-x_{0}$. 
Table 1. Central temperature difference and flow rates.

\begin{tabular}{cccccc}
\hline$\Delta T_{C}\left({ }^{\circ} \mathrm{K}\right)$ & $Q_{v 1}\left(\mathrm{~m}^{3} \cdot \mathrm{h}^{-1}\right)$ & Velocity $\left(\mathrm{m}^{\mathrm{s}} \mathrm{s}^{-1}\right)$ & $Q_{v 2}\left(\mathrm{~m}^{3} \cdot \mathrm{h}^{-1}\right)$ & Velocity $\left(\mathrm{m} \cdot \mathrm{s}^{-1}\right)$ & $b_{T}(\mathrm{~m})$ \\
\hline 33 & 386 & 0.14 & 366 & 0.11 & 0.55 \\
30 & 446 & 0.10 & 397 & 0.13 & 0.55 \\
21 & 576 & 0.15 & 577 & 0.13 & 0.63 \\
22 & 647 & 0.13 & 547 & 0.18 & 0.56 \\
14 & 720 & 0.12 & 840 & 0.09 & 0.84 \\
12 & 1044 & 0.11 & 976 & 0.15 & 0.78 \\
\hline
\end{tabular}

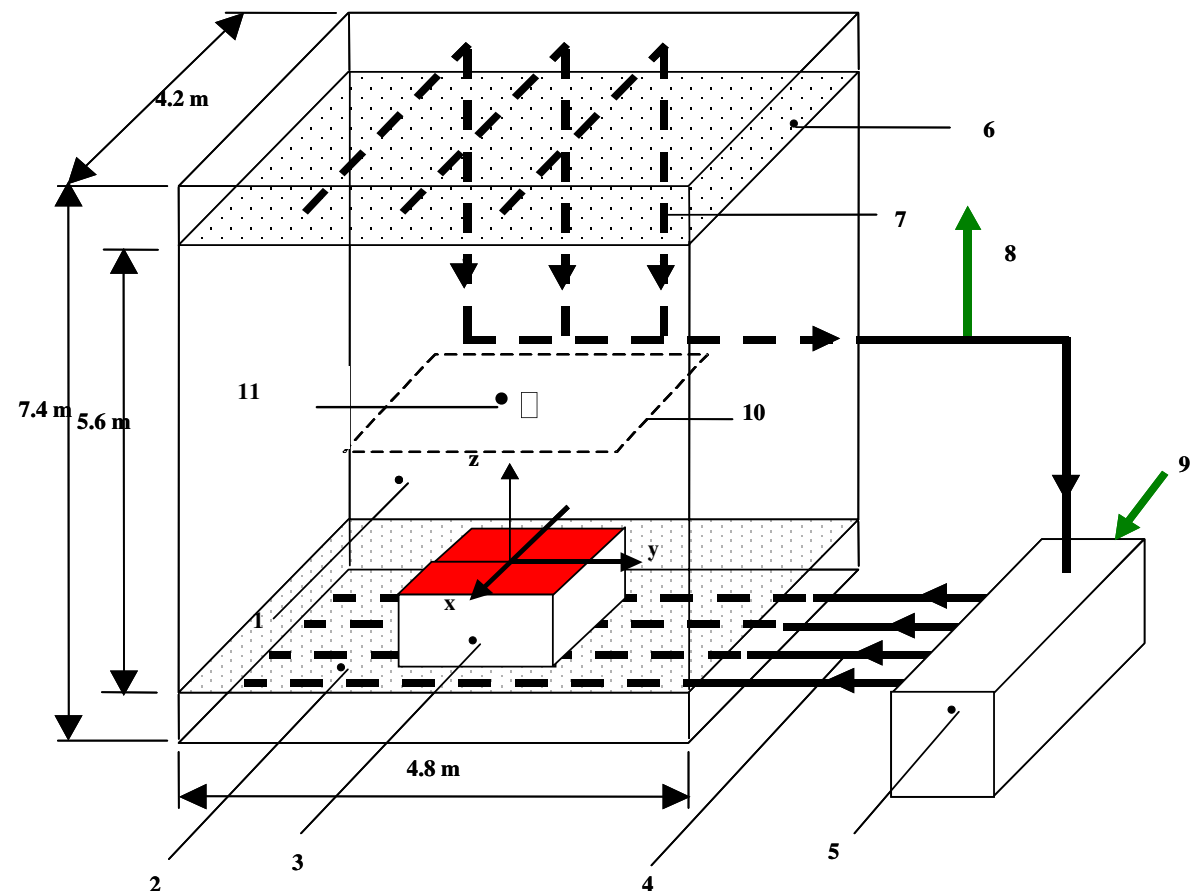

Fig. 4. Experimental installation. 1: Experimentation zone, 2: Perforated floor, 3: Heat source, 4: Inlet pipes, 5: Air conditioning unit, 6: Perforated ceiling, 7: Outlet pipes, 8: External outlet, 9: External inlet, 10: Hood inlet, 11: Hood inlet centre.

plume, assuming the hypothesis that $b_{T}$ is equal to $b$. The results in Table 1 give also the variations of the vertical component of velocity $w_{c}$ as a function of $\Delta T_{C}$. Considering columns 2 and 4 , the relative difference between the values of the flow rate, for a given $\Delta T_{C}$, does not exceed $10 \%$. So, the values obtained are considered to be valid.

\section{Materials and methods}

The Aeraulics Engineering Laboratory at INRS Vandoeuvre (Institut National de Recherche Scientifique à Vandoeuvre) has an experimental unit whose dimensions are characteristic of an industrial installation. Figure 4 provides a schema of the experimental installation, with a representation of two rectangular sources (ceiling height: $5.6 \mathrm{~m}$, base: $4.2 \mathrm{~m} \times 4.8 \mathrm{~m}$ ). The perforated floor $(2)$ of this unit allows the injection of air with controlled rate and temperature. The same flow rate is extracted from the upper part of the chamber (6). This unit was previously described in greater detail in Bouzinaoui et al. [10]. This figure also specifies the system of coordinates chosen.
The $z$ axis is vertical with an origin situated on the upper part of the considered source, the $y$ axis being parallel to the length of the modulus in the case of rectangular sources.

The laboratory also has heat sources of various shapes:

- an adjustable cylindrical surface (circular heating surface-the upper part of which is flat and horizontalalong with four lateral and independent heating surfaces);

- a horizontal, rectangular heating surface (several sources can be grouped together).

Figure 5 provides the measurements and shows the main geometric characteristics of the sources. All these sources have heating elements of the resistive type and are operated by a control and regulation system, enabling the operator to select different temperature values.

The installation developed in the laboratory is used to determine temperature and velocity fields. The relevant technical details can be found in the theses of Bouzinaoui [11] and Blaise [12]. With the rectangular sources, it was also possible to install a tracer gas injection system, using helium, within the immediate proximity of 

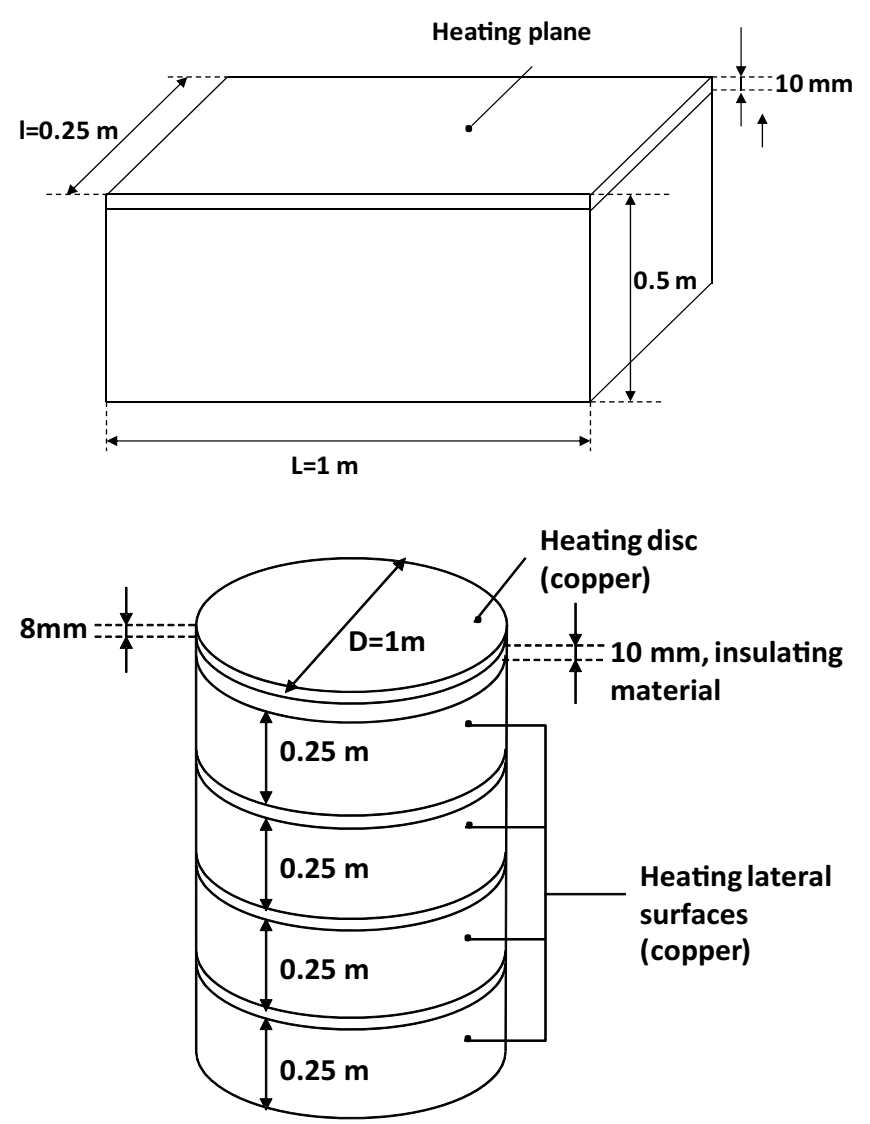

Fig. 5. Dimensions of cylindrical and rectangular sources.

the hot surface. This gas will be pulled along by the plume, simulating the convection of a non-reactive pollutant produced in the vicinity of the source. The concentration of helium was measured by taking samples of gases and by spectroscopic analysis.

A ventilation hood with an inlet surface measuring $1.5 \mathrm{~m} \times 1.5 \mathrm{~m}$ can be placed above rectangular sources. The extraction flow rate of the hood is adjustable. Similarly, the hood can be placed at different heights above the source and the centre of the hood may be shifted (or displaced) in the direction of the $x$ or $y$ axis. The capture efficiency of the hood was determined in conformity with the standards. It is defined as $\eta=\frac{\dot{m}_{c}}{\dot{m}_{e}}$, the ratio of mass flow rates captured at the outlet and at the inlet. It is determined as a function of concentrations measured by

$$
\eta=\frac{C_{3}-C_{1}^{\prime}}{C_{2}-C_{1}}
$$

where $C_{1}^{\prime}, C_{1}$ are the average concentrations of the tracer in the ambient atmosphere (before and after measurement).

$C_{2}$ is the average concentration of the tracer at the extraction duct outlet, the tracer being introduced at the duct entry.

$C_{3}$ is the average concentration of the tracer at the extraction duct outlet, the tracer being introduced at the level of the source. This determination was performed according to European standards [13].
The air flow rising in the plume, taken from the ambient environment, varies according to height and can be determined directly on the basis of the measurement of the vertical component $w_{c}$ of the velocity field, integrated over a given horizontal plane.

Experimental determination of the temperature, velocity and concentration fields produces a considerable amount of data. To extract the main characteristics of the field considered, a numerical tool based on the following equations was formulated in the laboratory:

$$
\begin{aligned}
T(x, y, z)-T_{a} & =\Delta T(x, y, z)=\Delta T_{c}(z) \exp (-f(x, y)) \\
w(x, y, z) & =w_{c}(z) \exp (-f(x, y)) \\
C-C_{a} & =\Delta C(x, y, z)=\Delta C_{c}(z) \exp (-f(x, y))
\end{aligned}
$$

where $x, y, z$ designate the coordinates of the measurement point.

The function $f$ which appears in (7)-(9) can be chosen by experimenters, and here, it takes the following form:

$$
\begin{aligned}
f(x, y)= & \left(x-x_{0}\right)^{2}\left(\frac{\cos ^{2} \theta}{B^{2}}+\frac{\sin ^{2} \theta}{A^{2}}\right) \\
& +\left(y-y_{0}\right)^{2}\left(\frac{\sin ^{2} \theta}{B^{2}}+\frac{\cos ^{2} \theta}{A^{2}}\right) \\
& +\left(x-x_{0}\right)\left(y-y_{0}\right)\left(\frac{1}{B^{2}}-\frac{1}{A^{2}}\right) \sin 2 \theta
\end{aligned}
$$

Naturally, the different parameters appearing in the expression of $\mathrm{f}$ depend on the nature of the field considered. According to this model, the isotherm, iso velocity and iso concentration lines of any horizontal plane are ellipses with a centre $x_{0}, y_{0}$, half axes $A$ and $B$. The orientation of the ellipse in the horizontal plane is given by the angle $\theta$ between the $\mathrm{x}$ direction and the major axis of the ellipse. There are many possibilities for function $f$ and the expression shown here is a compromise between the two extreme theoretical cases. For the point source, the isotherms are circles centred on the vertical axis of the plume and for the linear source, the isotherms are horizontal lines parallel to the source. Figures $6 \mathrm{a}-6 \mathrm{~d}$ provide an example of the application of the tool proposed. The case of the figures shown here is a flat, horizontal rectangular source of $1.5 \mathrm{~m}$ $\times 0.50 \mathrm{~m}$ whose temperature was raised to $350{ }^{\circ} \mathrm{C}$, represented by the grey rectangle. The isotherm lines shown correspond to a temperature $T=T_{a}+\Delta T_{C} / e$ for each horizontal plane considered, with $e=\exp 1=2.718 \ldots$ It can be seen that they are ellipses of which only one of the main axes evolves with height.

\section{Results}

\subsection{Dynamic and thermal fields}

The graph presented in Figure 7 shows an example of the evolution of the maximum temperature difference 


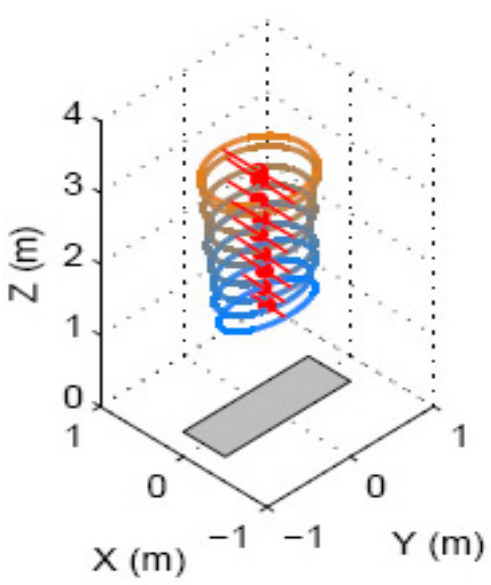

(a)

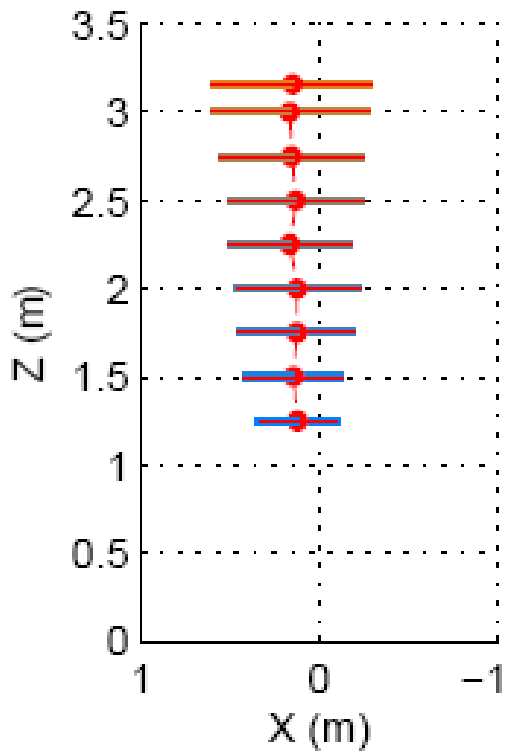

(c)

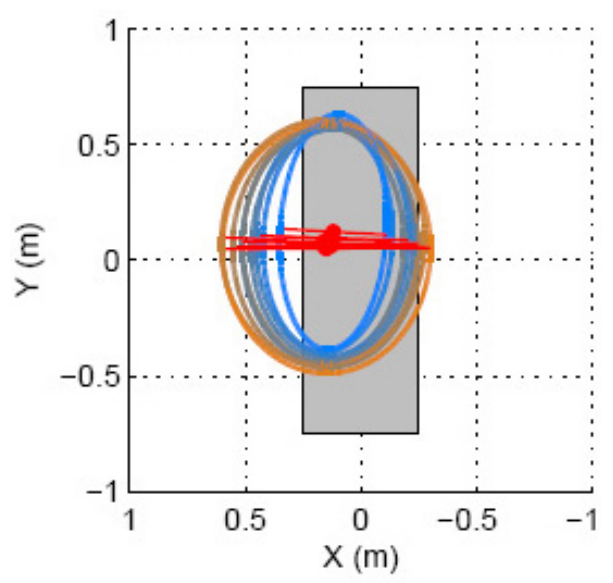

(b)

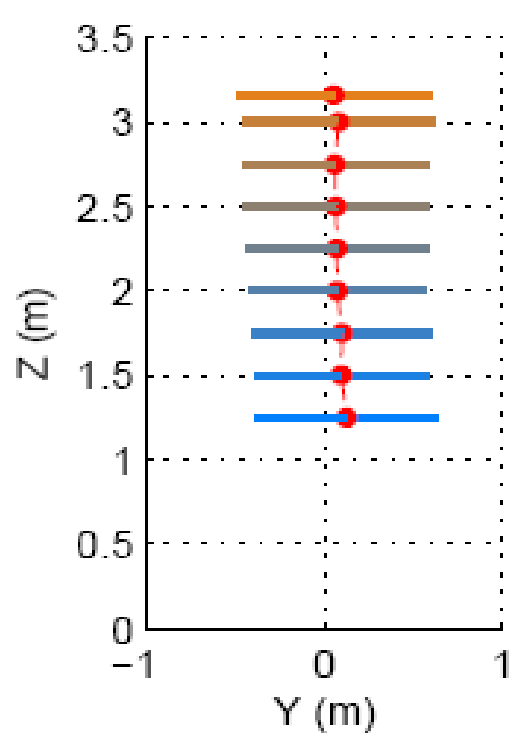

(d)

Fig. 6. Evolution of isotherms above a rectangular source. (a) Spatial view. (b) Projection on the $x y$ plane. (c) Projection on the $x z$ plane. (d) Projection on the $y z$ plane.

$\Delta T_{c}$, indicated on the plume axis as a function of $z$, the height of the plane of temperature determination. In this case, the source consists of a vertical cylinder of diameter $D=1 \mathrm{~m}$, with four distinct lateral areas of a height equal to $0.25 \mathrm{~m}$, at temperatures of $22{ }^{\circ} \mathrm{C}, 35^{\circ} \mathrm{C}, 65^{\circ} \mathrm{C}$ and $250{ }^{\circ} \mathrm{C}$, respectively. The circular horizontal upper part of the source was raised to $250{ }^{\circ} \mathrm{C}$ (case No. 1). The experimental values are compatible with an evolution of the shape $\left(z-z_{v}\right)^{-5 / 3}$, while the value of $z_{v}$, the height of the virtual origin, is obtained by using the least squares method. The exponent $-5 / 3$ shows that the measurement points are located in the far domain $z / D>2$. Given the results obtained, we consider it acceptable to propose the following approximation: $z_{v}=-(1.25 \pm 0.25) D$.

Figure 7 also shows a curve corresponding to a numerical simulation based on use of the Fluent software's finite volumes code. In the near zone where $z / D<1$,

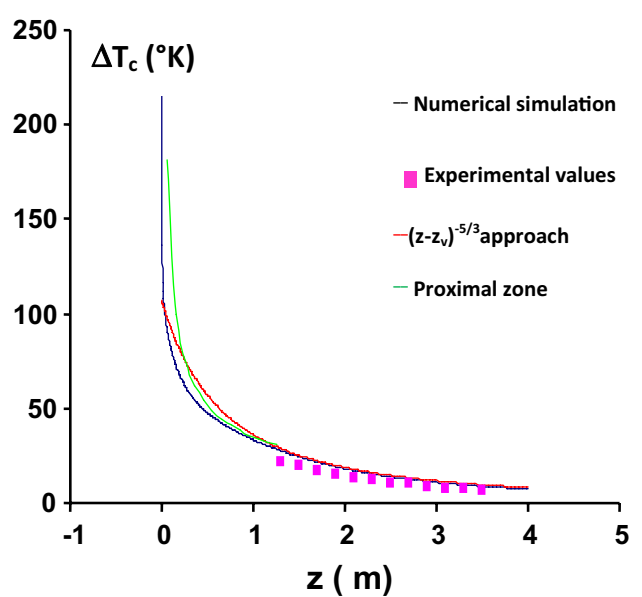

Fig. 7. Central temperature difference $\Delta T_{c}$ versus $z$. 


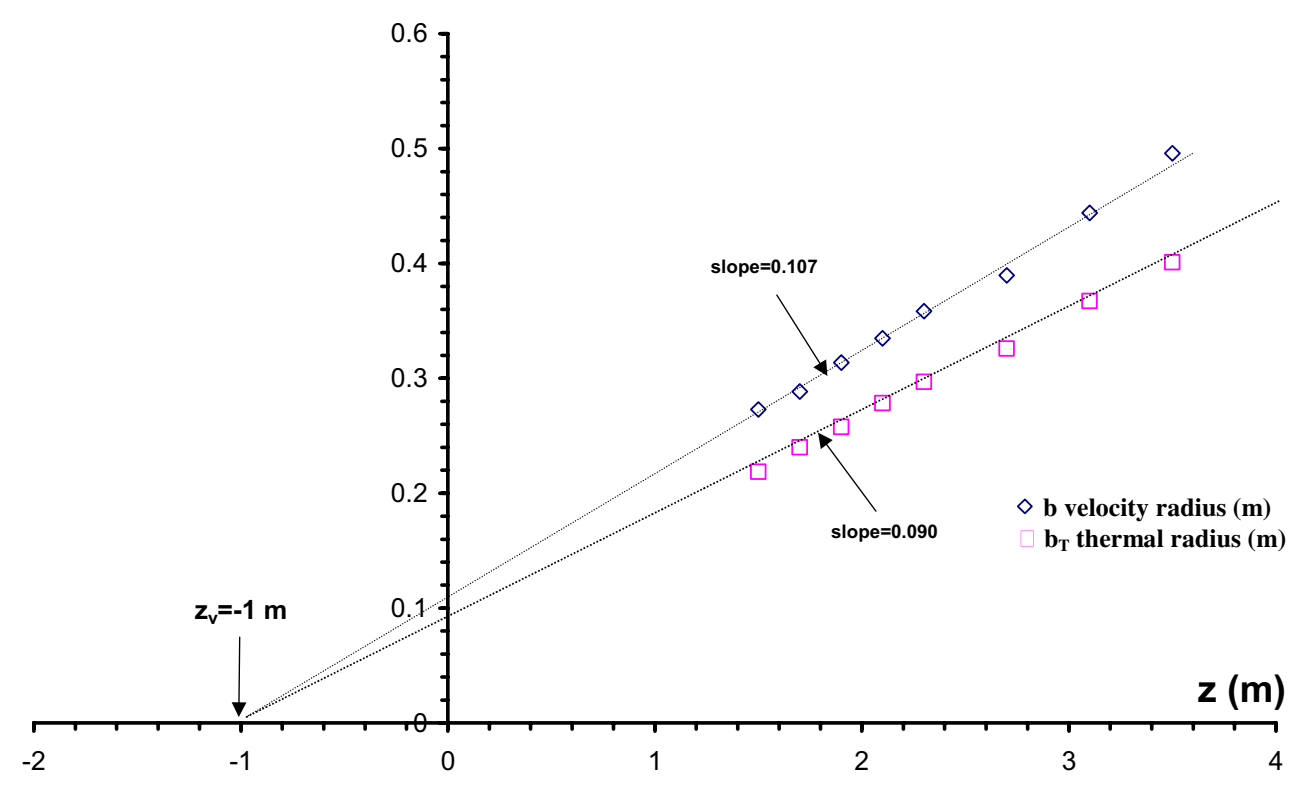

Fig. 8. Evolution of the radii with the height $z$ above the source (case No. 2)

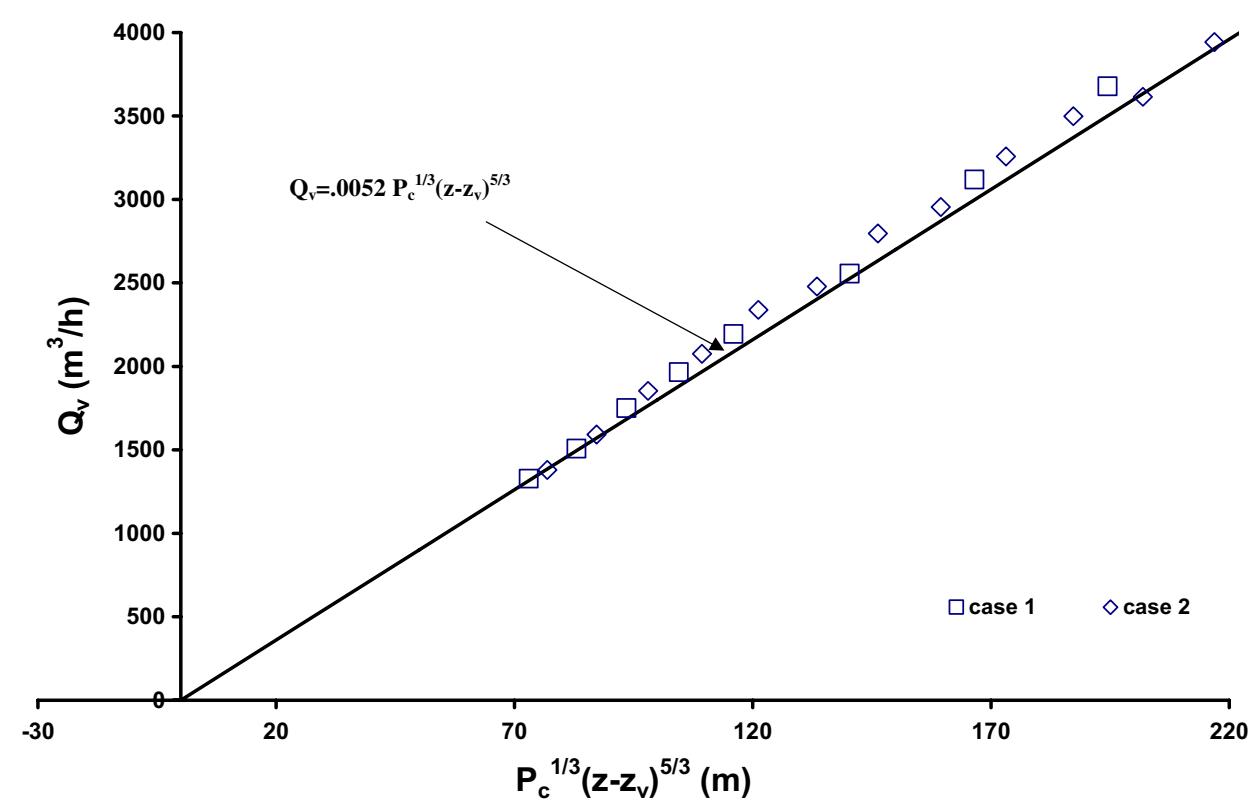

Fig. 9. Variation of the flow rate $Q_{v}$ with $P_{c}^{1 / 3}\left(z-z_{v}\right)^{5 / 3}$.

the approach with $\left(z-z_{v}\right)^{-5 / 3}$ was found to be unacceptable, and therefore, we are proposing a purely numerical approach based on least mean squares minimization $\left(z / D^{-0.55}\right.$. In this zone, the real geometry of the source appears to be the major influence factor and the notion of virtual origin loses its signification.

Measuring the vertical velocities enabled us to calculate the flow rate driven by the plume at a given height and to characterize its width using parameter $b$, defined by Equation (2). Figures 8 and 9 show the consistency of accuracy in virtual origin for these two magnitudes. They correspond to the use of cylindrical source. The case No. 1 was described previously in this paragraph, the temperatures being equal to $22{ }^{\circ} \mathrm{C}, 35{ }^{\circ} \mathrm{C}, 65{ }^{\circ} \mathrm{C}$ and $250{ }^{\circ} \mathrm{C}$ for the lateral hot surfaces and $250^{\circ} \mathrm{C}$ for the horizontal hot disk. For the case No. 2, temperatures reach $22^{\circ} \mathrm{C}$, $35{ }^{\circ} \mathrm{C}, 59{ }^{\circ} \mathrm{C}, 110{ }^{\circ} \mathrm{C}$ and $350{ }^{\circ} \mathrm{C}$, respectively.

For the specific case of rectangular sources, the aspect ratio, that is to say, the length/width ratio of the hot surface, can be varied by assembling several sources. Thus, the values of this ratio that have been tested are $1,2,3$ and 6 . For the lower values of this ratio, that is to say 1 or 2 , the results show that it is always possible to use formulae pertaining to the point source case. In contrast, 


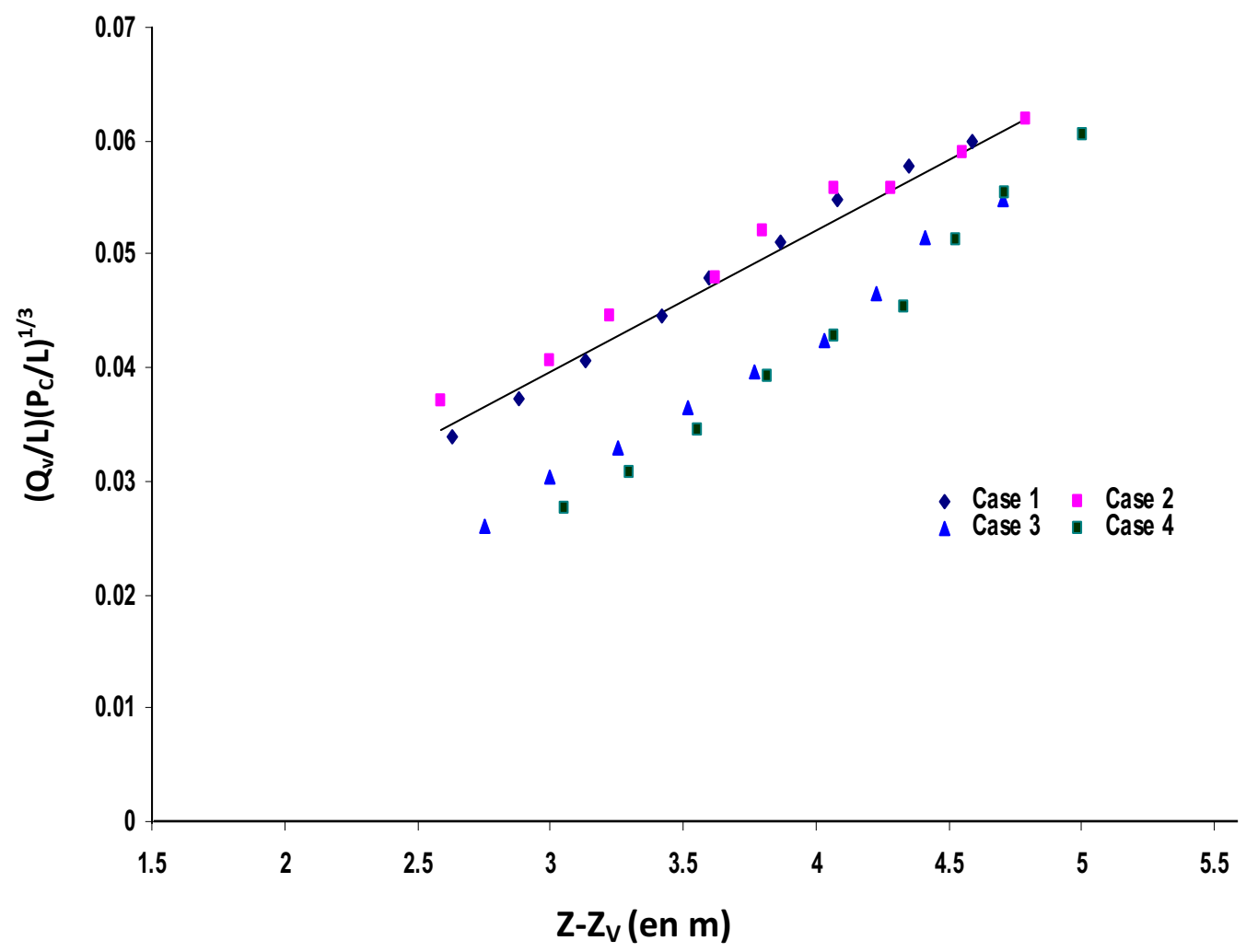

Fig. 10. Normalized flow rate as a function of $z-z_{v}$ (case No. 1, aspect ratio 6, surface temperature $623 \mathrm{~K}$; case No. 2, aspect ratio 3, surface temperature $593 \mathrm{~K}$; case No. 3 aspect ratio 2, surface temperature $423 \mathrm{~K}$, ; case No. 4, aspect ratio 1.5, surface temperature $393 \mathrm{~K})$.

for ratios 3 and 6 , Figure 10 shows that the experimental points can be grouped provided that the quantity $\left(\left(Q_{v} / L\right)\right.$ $\left.\left(P_{c} / L\right)^{-1 / 3}\right)$ is represented as a function of $z-z_{v}$, which corresponds to the case of the linear source (see Ref. [?]). It must be noticed that $L$ is the length of the rectangular source unit, see Figure 5. Any other choice like the width $l$ would produce an overestimation of the temperature.

\subsection{Concentration field and capture efficiency}

The concentration field was found to evolve in a similar manner to the temperature field, as can be seen in Figures 11 and 12. The velocity field appears to be the leading element, ensuring the convection of energy and also of the tracer gas. At a given height, the enlargement of the plume can be explained by heat or mass diffusion, more especially, in a direction perpendicular to the plume axis. Mainly, this diffusion is due to turbulence. Probably, the two diffusion coefficients vary in a similar manner, a hypothesis which must be confirmed by experimentation.

Naturally, the ratio $r_{D}$ of the convected flow rate $Q_{v}$ (at a height equal to that of the hood inlet) to the extracted flow rate $Q_{a}$ appears to be a fundamental parameter governing efficiency. Ensuring that this is the case of the hood centred in relation to the source, the experimental points can be grouped together in a single curve, as shown in Figure 13. Maximum efficiency was reached as

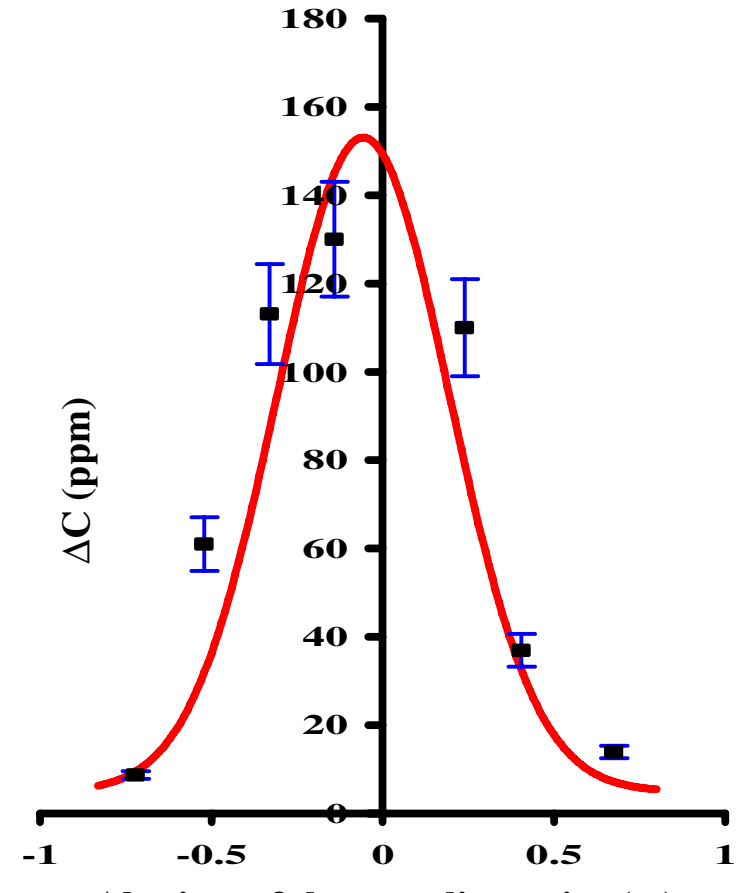

\section{Abscissa of the sampling point (m)}

Fig. 11. Concentration difference $\Delta C=C-C_{a}$ as a function of the abscissa $x$ (rectangular source, aspect ratio 3 , surface temperature $T_{s}=280{ }^{\circ} \mathrm{C}$, Helium flow rate $=((4.65 \pm 0.19) \times$ $\left.10^{-5} \mathrm{~m}^{3} \cdot \mathrm{s}^{-1}\right)$. 


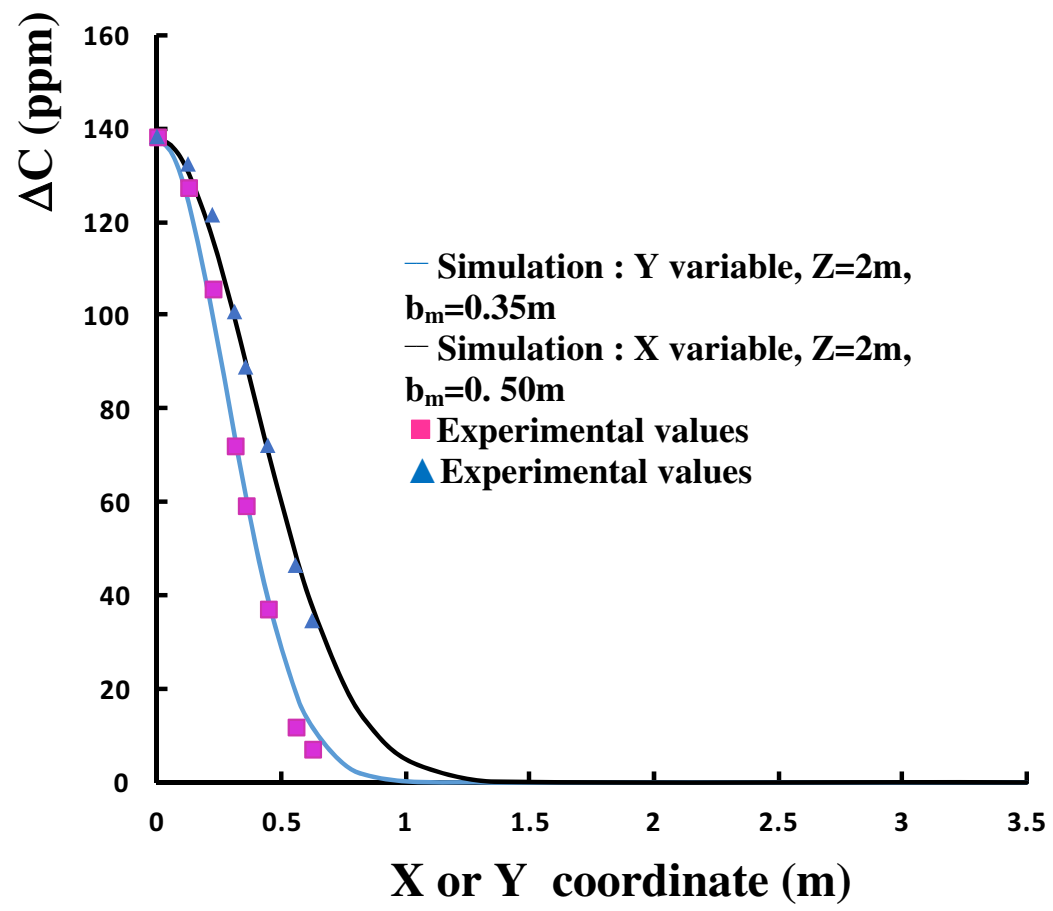

Fig. 12. Concentration difference versus $x$ or $y$ coordinate.

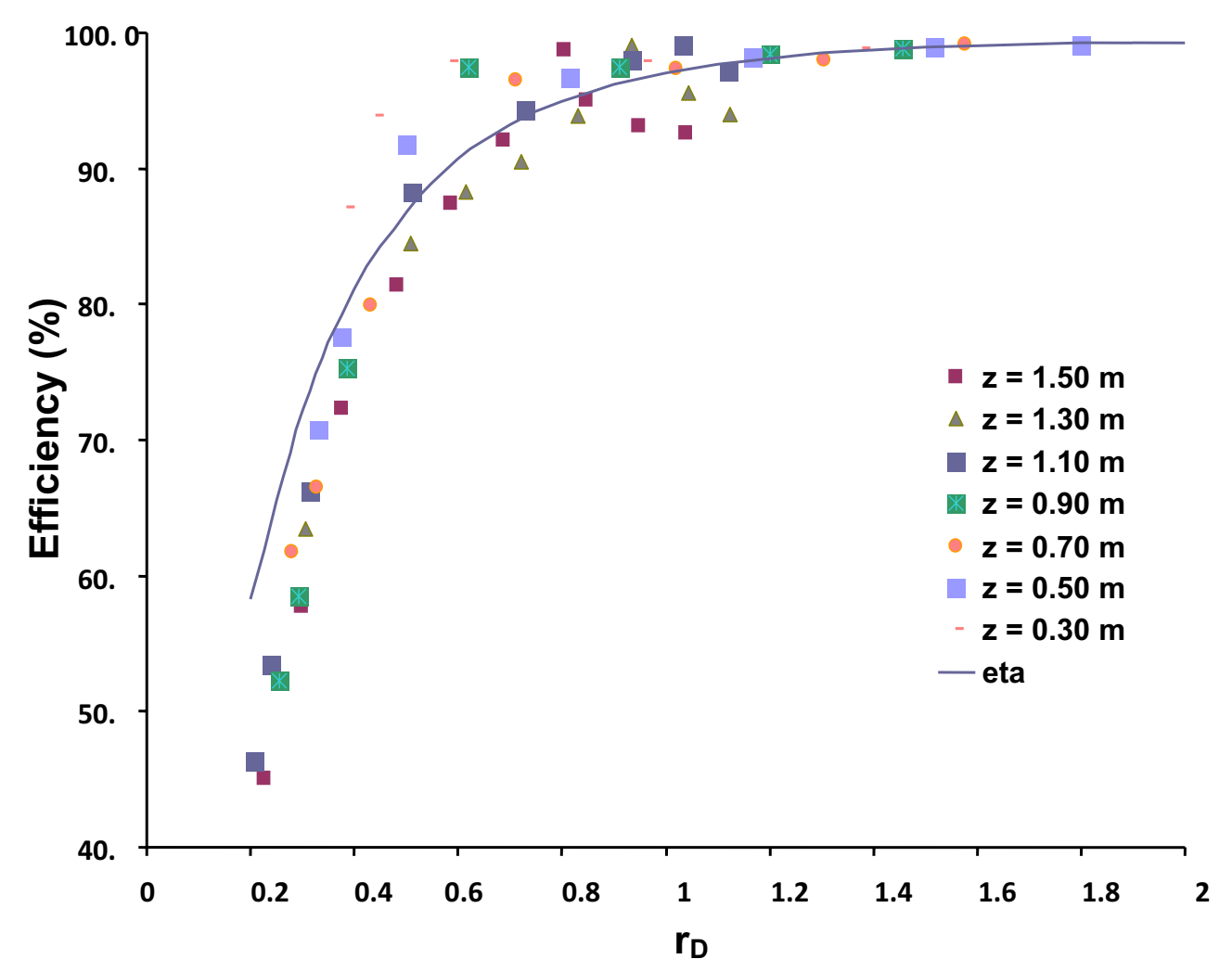

Fig. 13. Efficiency for different heights as a function of the flow rates ratio $r_{D}$. 


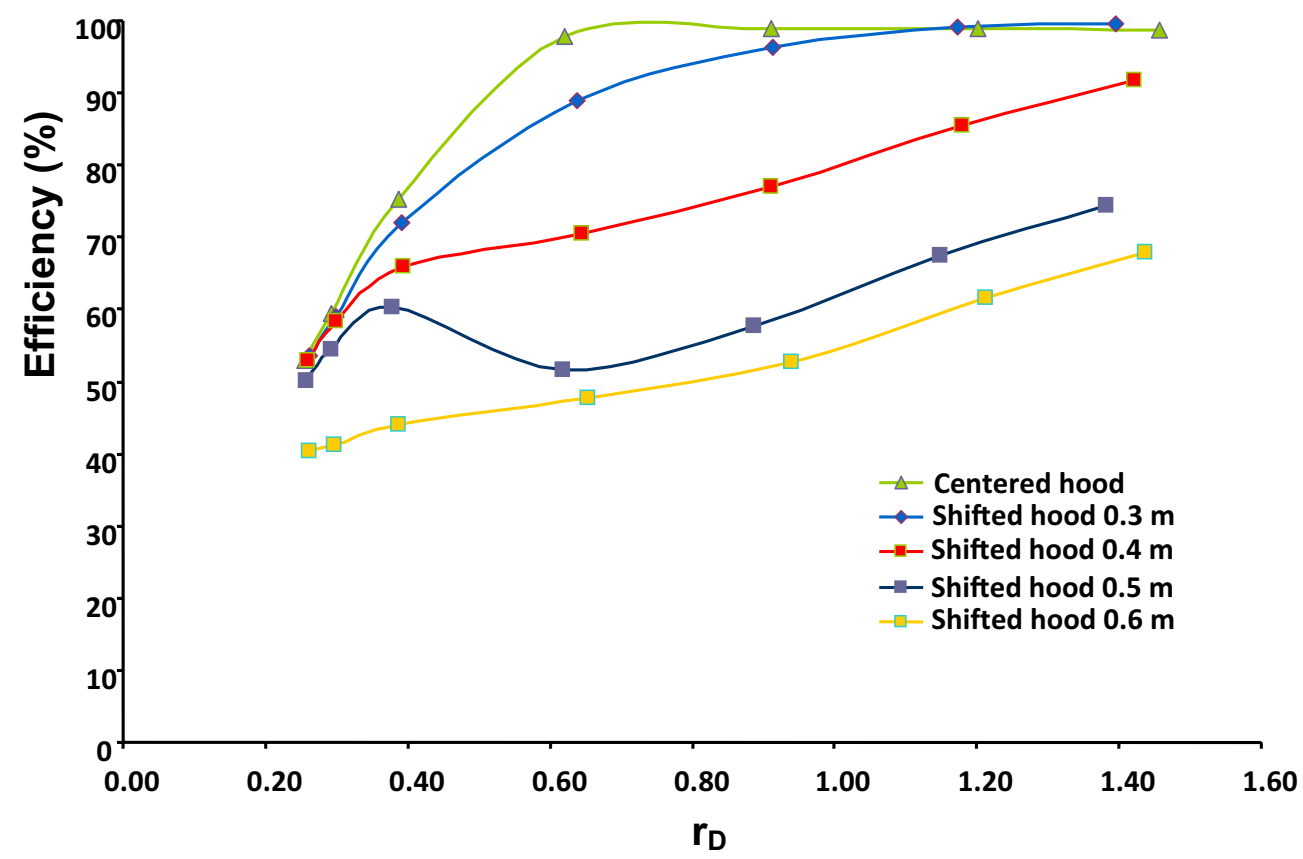

Fig. 14. Efficiency at $z=0.9 \mathrm{~m}$ for different shifts of the hood.

soon as $r_{D}$ approaches the value of 1 , independently of the position of the hood above the source. On this graph, the continuous line corresponds to the numerical approach

$$
\eta=1-\exp \left[1.05 r_{D}^{2}-4.58 r_{D}\right]
$$

approach based on a least mean squares minimization.

In industrial environment, plumes are very sensitive to any external phenomena (like a horizontal velocity in the ambient air) which may induces some inclination of the axis of the plume, leading to a defect of capture efficiency. To simulate these situations, the inlet of the hood has been translated relatively to the vertical axis of the source. Efficiency was found to decrease immediately when the hood was shifted transversally in relation to the source (see Fig. 14). It should be noted here that an increase to the suction flow rate was no longer sufficient to reach maximum efficiency in this situation.

\section{Conclusion}

In this paper, we have presented methods and tools that are useful to describe plumes generated by industrial heat sources of simple geometry (like vertical cylinders, horizontal rectangles). These tools enable the full description of air temperature, air velocity and pollutant concentration distributions above the sources. We also proposed formulae to evaluate the convected air flow rate as a function of height above the source. To remove pollutants that may be transported by the plume, a capture hood is generally used. We have proposed various relationships to properly design such a device. We have indicated corrections to the classical formulae for point sources, a distinction between the models according to the aspect ratio and an empirical approach to the zone situated near the source. In particular, by using the tracer gas method, we have experimentally determined the hood capture efficiency and expressed this quantity as a function of basic parameters: extraction flow rate, height of the hood inlet and its possible horizontal displacement with respect to the source, since the extraction efficiency is very sensitive to the position of the hood inlet relative to the position and expansion of the plume.

\section{Appendix 1}

\begin{tabular}{r|c}
\hline Point source & Linear source \\
\hline$w(x, y, z)=w_{c}(z) \exp \left(-(r / b)^{2}\right)$ & $w(x, y, z)=w_{c} \exp \left(-(y / b)^{2}\right)$ \\
\hline$w_{c}(z)=\left[\frac{3 g b \beta\left(\lambda^{2}+1\right)}{2 \pi \rho C_{p}}\right]^{1 / 3}$ & $w_{c}=\left[\frac{g \beta \sqrt{\left(\lambda^{2}+1\right) / 2}}{\rho \alpha C_{p}}\right]^{1 / 3}\left(p_{c}\right)^{1 / 3}$ \\
$\times\left[\frac{6 \alpha a}{5}\right]^{-2 / 3} P c^{1 / 3} z^{-1 / 3}$ & \\
\hline$\Delta T(x, y, z)=\Delta T_{c}(z)$ & $\Delta T(y, z)=\Delta T_{c}(z) \exp -(y /(b \lambda))^{2}$ \\
\hline$\Delta T_{c}(z)=\left[\frac{3 g b \beta\left(\lambda^{2}+1\right)}{2 \pi \rho \alpha C_{p}}\right]^{2 / 3}$ & $\Delta T_{c}=w_{c}^{2}(\pi g b \lambda)^{-1 / 2} z^{-1}$ \\
$\times\left[\frac{6 \alpha a}{5}\right]^{-4 / 3} P c^{2 / 3} z^{-5 / 3}$ & \\
\hline$b=\frac{5}{6} \alpha z$ & $Q=\frac{2}{\sqrt{\pi}} \alpha z$ \\
\hline$Q v=\pi b^{2} w_{c}$ & $Q L=2 w_{c} \alpha z$ \\
\hline
\end{tabular}

Here, $g$ is the acceleration due to gravity. The parameter $\lambda$ stands for the ratio of thermal radius to the dynamic 
one. It should be noted that $P_{c}$ is the power convected by the plume for a point source case, $p_{c}$ corresponding to the power by length unit, for the linear source case. The evolution of air density with temperature is supposed to follow the relation $\rho=\rho_{a}\left[1-\beta\left(T-T_{a}\right)\right], \beta$ being the air coefficient of thermal expansion, considered like a constant.

The parameter $\alpha$ is the entrainment coefficient. It traduces the fact that if a plume moves some air flow, this flow must be captured from the ambient air. More precisely, $\alpha$ is defined as following: $\alpha=-[r u]_{\infty} /\left(b w_{c}\right)$, where $[r u]_{\infty}$ is the external flow rate at a given height and $\mathrm{u}$ is the radial velocity.

\section{References}

[1] W. Schmidt, Turbulent propagation of a stream of heated air, Z. Angew. Math. Mech. 21 (1941) 265-351

[2] B.R. Morton, G. Taylor, J.S. Turner, Turbulent gravitational convection from maintained and instantaneous sources, Pro. Roy. Soc. A 234 (1956) 1-23

[3] J.L. McKernan, M. Ellenbecker, C. Holcroft, M. Petersen, Evaluation of a proposed Equation for Improved Exothermic Process Control, Ann. Occup. Hyg. 5 (2007) 357-369

[4] W.C.L. Hemeon, Exhaust for hot processes in Hemeon's. plant and process ventilation, edited by D.J. Burton, 3nd edition, Lewish Publishers, New-York, 1999, pp. 117-147

[5] G.G. Rooney, P.F. Linden, Similarity considerations for non-Boussinesq plumes in an unstratified environment, J. Fluid Mech. 318 (1996) 237-250
[6] E. Mundt, The performance of displacement ventilation systems: experimental and theoretical studies, Ph.D. thesis, KTH-Royal Institute of Technology, Stockholm, 1996

[7] ACGIH Industrial Ventilation, A Manual of Recommended Practice, 25th Edition, Kemper Woods Center, Cincinnati, Ohio, 2004, 3-21, pp. 3-19

[8] The Industrial Ventilation Guidebook, edited by E. Tahti, H.D. Goodfelow, 2001

[9] T. Fanneløp, D. Webber, On buoyant plumes rising from area sources in a calm environment, J. Fluid Mech. 497 (2003) 319-334

[10] A. Bouzinaoui, R. Devienne, J.-R. Fontaine, An experimental study of the thermal plume developed above a finite cylindrical heat source to validate the point source model, Exp. Thermal Fluid Sci. 31 (2007) 649-659

[11] A. Bouzinaoui, Panache développé au-dessus d'une source thermique : Stratification du milieu environnant en enceinte ventilée, Ph.D. thesis, Université Henri Poincaré, Nancy, France, 2004

[12] J. Blaise, Influence de la géométrie d'une source thermique sur le développement du panache. Ph. D thesis, Université Henri Poincaré, Nancy, France, 2008, http:// petale.univ-lorraine.fr/index.html

[13] NF X10-141, Mesurage de débits de gaz dans des conduites fermées, Méthodes par traceur. Partie 1, généralités, 1982

[14] R. Devienne, J.-R. Fontaine, Experimental characterisation of a plume above rectangular thermal sources. Effect of aspect ratio, Build. Environ. 49 (2012) 17-24 